\title{
Effects of Homeopathic Preparations of Mercurius corrosivus on the Growth Rate of Severely Mercury-Stressed Duckweed Lemna gibba L.
}

\author{
Tim Jäger $^{1, \dagger}$ Sandra Würtenberger ${ }^{2}$ Stephan Baumgartner ${ }^{1,3}$ \\ ${ }^{1}$ Institute of Integrative Medicine, University of Witten/Herdecke, \\ Germany \\ 2 Scientific and Regulatory Affairs, Hevert-Arzneimittel GmbH \& Co. \\ KG, Nussbaum, Germany \\ ${ }^{3}$ Society for Cancer Research, Hiscia Institute, Arlesheim, \\ Address for correspondence Stephan Baumgartner, Dr. sc. nat., \\ University of Witten/Herdecke, Institute of Integrative Medicine, \\ Gerhard-Kienle-Weg 4, 58313 Herdecke, Germany \\ (e-mail: Stephan.Baumgartner@uni-wh.de).
} Switzerland

Homeopathy 2019;108:128-138.

\begin{abstract}
Background We developed a bioassay with mercury-stressed duckweed (Lemna gibba L.) to study potential effects of homeopathically potentised mercury(II) chloride (Mercurius corrosivus [Merc-c.]). The response of this bioassay to homeopathic treatments as a function of stress intensity was also of interest.

Methods Duckweed was severely stressed with mercury(II) chloride for 48 hours. Afterwards plants grew in either Merc-c. (seven different potency levels, $24 \mathrm{x}$ to $30 \mathrm{x}$ ) or water controls (unsuccussed and succussed water) for 7 days. Growth rates of the frond (leaf) area were determined using a computerised image analysis system for different time intervals between the measurements on days 0,3 and 7. Three independent experiments with potentised Merc-c. each were evaluated. Additionally, three water control experiments were analysed to investigate the stability of the experimental setup (systematic negative control [SNC] experiments). All experiments were randomised and blinded.

Results Unsuccussed and succussed water did not significantly differ in terms of duckweed growth rate. The SNC experiments did not yield any significant effects, providing evidence for the stability of the experimental system. Data from the two control groups and the seven treatment groups (Merc-c. 24x-30x) were each pooled to increase the statistical power. Duckweed growth rates for day 0 to 3 were reduced $(p<0.05)$ after application of Merc-c. compared with the controls. Growth rates for day 3 to 7 were not influenced by the homeopathic preparations.

Keywords

- Lemna gibba L.

- duckweed

- homeopathy

- mercury

- Mercurius corrosivus

Conclusions The present test system with Lemna gibba $\mathrm{L}$. that was severely stressed by mercury yielded evidence for specific effects of Merc-c. $24 x$ to $30 x$, namely a growth reduction in the first time period (day $0-3$ ). This is in contrast to former experiments with slightly arsenic-stressed duckweed, where a growth increase was observed in the second time period (day 2-6). We hypothesise that the differing results are associated with the level of stress intensity (severe versus slight).
\end{abstract}

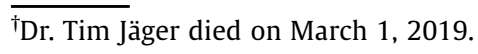

received

July 10, 2018

accepted after revision

October 23, 2018

published online

January 30, 2019
DOI https://doi.org/

10.1055/s-0038-1676464. ISSN 1475-4916.
Copyright $\odot 2019$ The Faculty of Homeopathy
License terms

(c) (i) $\ominus$ (요 


\section{Introduction}

Homeopathy is a widely used complementary therapy. Although used worldwide, ${ }^{1-3}$ the efficacy of homeopathic medicines remains a topic of controversial debate. ${ }^{4-7}$ The discussion centres on the fact that homeopathy can use ultrahighly diluted medicines beyond the inverse of the Avogadro constant. Therefore, basic research is of considerable interestnot only to investigate any effects of homeopathic medicines, but also to develop test systems to identify the mode of action. As the mode of action is still unknown and external influences have yet to be fully identified, ${ }^{8-10}$ reproducibility of results in basic research in homeopathy constitutes an ongoing challenge. ${ }^{11}$ Reliable and stable test systems are therefore needed as a first step towards addressing the question of whether homeopathic potencies can be distinguished from corresponding controls. In a second step, the underlying mode of action can then be narrowed down by analysing the influence of targeted exposure of homeopathic preparations to physical energy in different forms (autoclaving, electromagnetic fields, etc.). Such experiments are also important to give manufacturers and users information regarding possible interferences related to the production process and storage of homeopathic medicines. To achieve this, specific properties of homeopathic potencies can either be examined directly by physico-chemical measuring methods or indirectly by bioassays.

Duckweed is a well-standardised and established subject for bioassay in ecotoxicology. ${ }^{12-16}$ Assuming that test systems with stressed organisms will be more stable with respect to the effects of homeopathic preparations-compared with test systems using healthy organisms ${ }^{17-20}$-duckweed was stressed before application of potentised preparations. Previous studies using arsenic $(\mathrm{V})$ as a stressor found the system to be very stable, with growth-increasing effects of Arsenicum album potencies reproducibly observed. ${ }^{21}$

The aim of this study is to examine whether duckweed assay can be applied to other research questions in homeopathy research. One such question is whether the observed arsenic(V) stress alleviation effect can be generalised to other inorganic stressors. We therefore chose mercury as an alternative stressor to investigate the stability of the system and the response to other potentised substances. Areas of further interest include the response of this bioassay to homeopathic treatments as a function of stress intensity.

In this article, we present three independent experiments, which examine the influence of potentised Mercurius corrosivus (Merc-c.) on severely stressed duckweed. In a blinded, randomised set-up, stressed duckweed was treated with Merc-c. in seven potency levels (from $24 \mathrm{x}$ to $30 \mathrm{x}$ ) and compared with controls (unsuccussed and succussed water) in terms of their influence on the plant's growth rate. The stability of the system was tested by three independent systematic negative control (SNC) experiments.

Merc-c. was selected also because mercury potencies have a long tradition and importance in homeopathy as well as in anthroposophical medicine. In addition, the use of mercury in medicine is the subject of critical discussion in light of the Minamata Convention on Mercury initiated by the United Nations Environment Programme. ${ }^{22,23}$ Research on these substances is therefore of particular interest. Another longterm goal of our working group is to investigate the similia principle in varying stressors and potencies applied in basic research assays.

\section{Materials and Methods}

\section{General Experimental Design}

A single experiment comprised 60 beakers with Lemna gibba L. (-Fig. 1). For each experimental parameter $(n=15$ in total, $n=14$ letter-coded samples and 1 open control condition, see below), four replicates were used and randomly allocated in a fixed blocked randomisation scheme. The 14 coded samples consisted either of seven potency levels (from $24 \mathrm{x}$ to $30 \mathrm{x}$ ) of Merc-c. or of seven independent control preparations (three samples of unsuccussed water and four samples of one-time succussed water), or-in the case of the SNC experiments-of 14 unsuccussed water samples coming from the same source. After preparation, all test solutions
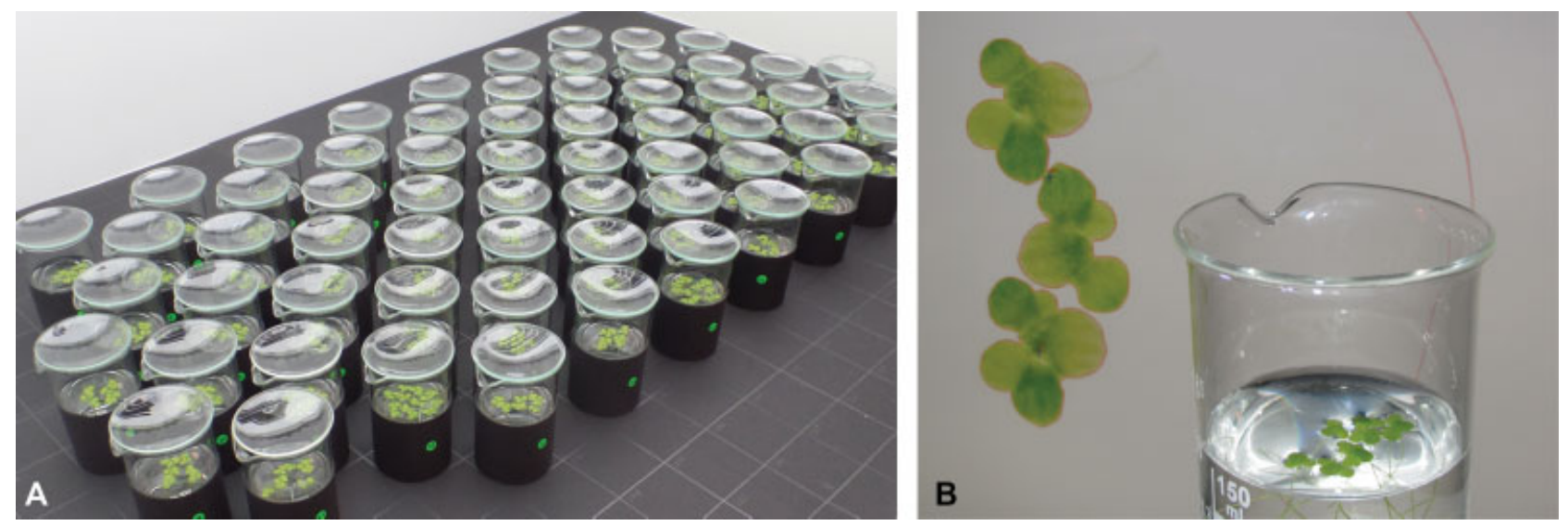

Fig. 1 (A) Experimental set-up of a single experiment in the growth chamber (60 beakers with Lemna gibba L.). For each experimental parameter ( $n=15$ in total), four replicates were used and allocated in a fixed blocked randomisation scheme. The 15 experimental conditions consisted of 14 letter-coded samples and one additional open control with unstressed duckweed (the latter control was not used for statistical evaluation). (B) Single beaker with duckweed; in the background an example of frond area analysed using the image analysis system. 
were randomised and coded (blinded) by a person not involved in the experiments. Duckweed was stressed with mercury for 48 hours. Subsequently, the plants were grown in either potentised substances or water controls for 7 days. Growth rate of fronds was determined for two different time intervals (day 0-3 and 3-7). Furthermore, we conducted three full-size experiments with pure water as the only treatment parameter (SNC experiments) to investigate the stability of the experimental set-up over the entire study period. Thus, six experiments were conducted in total.

Preparation of Potentised Test Solutions and Controls A detailed description of the sample preparation has been given in previous publications. ${ }^{21,24}$ In brief, all test solutions for one experiment (potencies and controls) were freshly prepared, using the multiple glass method, between 7 a.m. and $10 \mathrm{a} . \mathrm{m}$. on the day of the experiment from the same batch of reverse osmosis water (Arium 61316; Satorius Stedim Biotech GmbH, Göttingen, Germany) prepared from tap water (Arlesheim, Switzerland).

For the potentisation process, Erlenmeyer flasks of Duran glass ( $\leq 6 \mathrm{x}$ : $250 \mathrm{~mL}, \geq 7 \mathrm{x}: 500 \mathrm{~mL}$, Schott, Mainz, Germany) were used. Fifteen millilitres of potency stock solution (0.5 $\mathrm{g} / \mathrm{L} \mathrm{HgCl}_{2}$; Sigma-Aldrich, Buchs, Switzerland) were added to $135 \mathrm{~mL}$ water to produce the first potency level. Potentisation was performed according to a previously used standard protocol: ${ }^{21}$ the Erlenmeyer flask was first agitated once upside-down to generate a vortex; after the vortex had calmed down, the flask was shaken downwards a second time causing chaotic agitation of the water. These two steps were repeated 12 times. For the next potency level, $15 \mathrm{~mL}$ of this solution were added to the next potentisation vessel containing $135 \mathrm{~mL}$ of water and agitated in the same manner. At potency level $7 x$, the flask size was changed from 250 to $500 \mathrm{~mL}$, and the filling volume rose to $350 \mathrm{~mL}$; thus, $35 \mathrm{~mL}$ of the former potency level were added to $315 \mathrm{~mL}$ of water. This process of successive 10 -fold dilution and vigorous shaking proceeded until the potency step 30x was accomplished.

Two types of controls were prepared: unsuccussed water (c0) and succussed water ( 1 ), corresponding to water $1 \mathrm{x}$, shaken analogously to the potencies described above. Three samples of unsuccussed water were prepared in three $500 \mathrm{~mL}$ of Erlenmeyer flasks, and four samples of succussed water in four identical Erlenmeyer flasks. These controls were chosen in line with considerations discussed in detail elsewhere. ${ }^{25}$

From the potencies prepared, seven potency levels (from $24 \mathrm{x}$ to $30 \mathrm{x}$ ) were used for the experiments. Aiming at investigating possible differences in efficacy between single potency levels, a series of consecutive potency levels was used. In all these potency levels, the concentration of $\mathrm{HgCl}_{2} / \mathrm{L}$ is beyond the Avogadro limit. Together with the seven control preparations (see above), 14 samples were prepared in total. These 14 test solutions were randomised and coded (blinded) by a person not involved in the experiments and by manual random assignment of a double letter code from a pre-defined list.

\section{Experimental Procedure}

For the duckweed bioassay, axenic (pure) stock cultures of duckweed Lemna gibba L. (clone no. 9352) were grown according to a standard of the International Organization for Standardization ${ }^{12}$ first on solid, then in liquid modified Steinberg medium (moStM; all ingredients, Fluka, Buchs, Switzerland) to acclimatise the plants to the experimental conditions and obtain large number of plants under controlled laboratory conditions. The medium was changed weekly to achieve rapid, close to exponential, growth. It was assured that growth would not be restricted (e.g. due to space limitations or nutrient restrictions).

After a 7-day growth period, moStM was last changed 48 hours before starting the experiment. Plants $(7.5 \mathrm{~g})$ were transferred to one vessel containing $2000 \mathrm{~mL}$ of freshly prepared moStM to ensure identical nutrient concentration when adding $5 \mathrm{mg} / \mathrm{L}$ of mercury(II) chloride $\left(\mathrm{HgCl}_{2}\right.$; SigmaAldrich, Buchs, Switzerland). Fronds that were malformed or severely damaged were removed from the vessel 24 hours before starting the experiment. ${ }^{21}$ After 48 hours of poisoning, the experiments were started, without mercury(II) chloride in nutrient solution.

On the day of the experiment, plants without visible lesions, chlorosis or necrosis were selected from the vessel. Test specimens were sorted according to number of fronds, similar size, colour and form. Three plants each were used as starter culture for all beakers containing test solutions or controls respectively.

A single experiment comprised 60 beakers ( - Fig. 1). Fifteen experimental parameters were investigated in four replicate beakers each ( $15 \times 4=60$ beakers). The 15 parameters consisted of 14 letter-coded samples (seven potency levels of a given substance and seven control preparations, see above) and one additional open control condition (parameter) with unstressed duckweed. The latter control was used only to determine the degree of damage and did not enter the statistical evaluation of the experiments with potentised preparations.

For each experiment, $50 \mathrm{~mL}$ of moStM were poured (Bottletop dispensing head, $50 \mathrm{~mL}$, Brand; Wertheim, Germany) into 60 beakers each ( $150 \mathrm{~mL}$, SIMAX; Kavalier, Sázava, Czech Republic). Then $50 \mathrm{~mL}$ of 14 coded samples in four replicates each was added to the 56 beakers. For the one open control condition, $50 \mathrm{~mL}$ of water was added to four beakers each.

The sorted stressed duckweed colonies were carefully put into the 56 beakers for the coded samples at random. Sorted unstressed duckweed was placed into the four beakers of the open control. Frond area per beaker was measured at the beginning of the experiment (day 0 ), and on day 3 and 7 using a camera (D200; Nikon, Tokyo, Japan; photographic lens: AF-S Nikkor 17-55 mm 1:2.8G ED; Nikon, Tokyo, Japan) and an image processing system (medeaLAB imaging system count \& classify, version 6.7; Medea AV, Erlangen, Germany).

Experiments were conducted in a plant growth chamber, specially constructed to enhance homogeneity of light intensity, temperature and air velocity and to avoid vibrations during the experiment. Duckweed was illuminated with fluorescent lights $\left(145 \pm 4.9 \mu \mathrm{mol}\right.$ photons $\mathrm{m}^{-2}$ second ${ }^{-1}$ 
PAR, F32 T8/TL 741, Philips; Andover, Massachusetts, USA) for 16 hours/day. Mean air temperature was $20.1^{\circ} \mathrm{C} \pm 0.5^{\circ} \mathrm{C}$, mean temperature of moStM $22.1^{\circ} \mathrm{C} \pm 0.4^{\circ} \mathrm{C}$ (Endotherm, Dornach, Switzerland) and mean relative humidity was $41 \% \pm 9 \%$ (EBI-20-TH, Ebro, Ingolstadt, Germany).

The average growth rate per day $(r)$ based on the measured frond area was calculated for two test intervals (day 03 and day 3-7) according to the equation: $r=\left(\ln x_{\mathrm{t} 2}-\ln x_{\mathrm{t} 1}\right) /$ $\left(t_{2}-t_{1}\right)$, where $x_{t 1}$ is the value of observation parameter at day $t_{1}, x_{\mathrm{t} 2}$ is the value of observation parameter at day $t_{2}$ and $t_{2}-t_{1}$ is the time interval between $x_{\mathrm{t} 1}$ and $x_{\mathrm{t} 2}$ in days. More details concerning the procedures of the duckweed bioassay have been described elsewhere. ${ }^{24}$

\section{Statistical Analysis}

All experiments (two reproduction series with three experiments each) yielded a total of 1,008 data points (six experiments $\times 56$ beakers $\times$ three time points) that were transformed into 672 growth rate data values for the final statistical evaluation (day 0-3 and day 3-7). Due to careful experimentation, there were no missing data.

Data from the three SNC experiments were used to estimate the variability of the bioassay. We grouped the data of the 56 beakers of every single experiment into 14 groups of four replicates (beakers) and calculated mean values for these 14 sub-groups for frond area-related specific growth rate (day $0-3$ and 3-7 each). Based on these 14 values, the coefficient of variation $(\mathrm{CV}=$ standard deviation [SD] $\times 100 /$ mean) was calculated for three time intervals in every single experiment.

Regarding a possible succussion effect, data of the unsuccussed (c0) and succussed water controls (c1) of experiments with potentised substances were analysed using a two-way analysis of variance (ANOVA) F-test for independent samples.

A comparison of growth rate $(r)$ data between pooled potencies and pooled water controls (succussed and unsuccussed) was evaluated for statistical significance based on two-way ANOVA F-tests for independent samples. In all statistical analyses, the level of significance was $\alpha=0.05$. An interaction term between experiment number and treatment was included in the statistical model to be able to observe possible effect-modulating factors associated with the date of the experiment. Planned comparisons were evaluated with the least significant difference (LSD) test only if the corresponding global F-test was significant $(p<0.05)$ (Fisher's protected LSD). This constitutes a good safeguard against type I as well as type II errors. ${ }^{26}$

Levene's test was conducted to determine homogeneity of variances. Data distribution was evaluated graphically by quantile-quantile plots. All data were analysed using the software JMP Version 12 (JMP, Version 12.2.0, SAS; Cary, North Carolina, USA).

\section{Results and Discussion}

\section{Degree of Damage}

The influence of the poisoning with mercury was determined by comparing the growth rate of the pooled data of the unsuccussed ( $\mathrm{c} 0$ ) and succussed (c1) water control groups to the open control group without mercury poisoning. On the average of all three experiments, mercury-treated duckweed exhibited an area-related growth rate $(r)$ for day 0 to 3 of approximately $51 \%$ compared with duckweed growing without mercury $\left(r_{\text {with mercury }}=0.22 \mathrm{~d}^{-1}, r_{\text {without mercury }}=0.43\right.$ $\left.\mathrm{d}^{-1}\right)$ and for day 3-7 of approximately $84 \%\left(r_{\text {with mercury }}\right.$ $=0.38 \mathrm{~d}_{-1}, r_{\text {without mercury }}=0.45 \mathrm{~d}^{-1}$ ).

\section{Control Experiments}

The stability of the experimental set-up was investigated in three SNC experiments. These revealed very small CV for all outcome parameters measured (0.9-2.3\%, see - Table 1$)$. The CV decreased for the subsequent growth period, an observation that is in accordance with the hypothesis of a decreasing variation in growth for less stressed organisms $\left(\mathrm{CV}_{\text {day }} 0_{-}\right.$ $3>\mathrm{CV}_{\text {day 3-7 }}$ ). Regarding variability of the measured outcome, the bioassay with stressed duckweed is superior to other model systems using stressed plants in homeopathic basic research, since typical CVs are in the order of 10 to $80 \%$ in other model systems. ${ }^{27-29}$ Therefore, we conclude that our test system with severely mercury-stressed duckweed showed a very low standard deviation.

In the statistical analysis (performed in an absolutely identical manner to the experiments with Merc-c., see below), the global ANOVA F-tests yielded no significant effects for the outcome parameter calculated for treatment (here 14 sham treatments, water only) for the two test intervals (day 0-3 and day 3-7). Thus, false-positive results caused by uncontrolled influences during the experiment (e.g. systematic errors due to spatial gradients in light intensity or temperature) could be excluded with a very high degree of certainty. Also, the analyses for interaction of treatment with experiment number for the two test intervals (day 0-3 and day 3-7) yielded no significant effects (-Table 2, Series SNC).

The primary evaluation of the systematic negative control experiments was based on the randomisation code of the Merc-c. experiments (number allocations of the $14 \times 4$ beakers to the seven sham treatment or seven sham control groups per experiment) in the same sequence of the experiments. To further confirm that the Merc-c. experiments might not have generated false-positive results by chance, we additionally analysed the data from the three SNC

Table 1 Coefficient of variation (CV) for all outcome parameters in the three systematic negative control (SNC) experiments

\begin{tabular}{|l|l|l|}
\hline \multirow{2}{*}{ Experiment no. } & \multicolumn{2}{|l|}{ CV of growth rate $(\mathbf{r})$} \\
\cline { 2 - 3 } & day $\mathbf{0 - 3}$ & day $3-7$ \\
\hline SNC exp. no. 1 & 2.28 & 0.94 \\
\hline SNC exp. no. 2 & 2.24 & 1.20 \\
\hline SNC exp. no. 3 & 1.86 & 1.27 \\
\hline Mean & 2.13 & 1.14 \\
\hline
\end{tabular}

Note: CV was calculated based on mean values of 14 groups of four replicates (total 56 beakers) in one experiment. 
Table 2 Analysis of variance (ANOVA) analysis of the two experimental series (one with the test substance Mercurius corrosivus and one with systematic negative control [SNC] experiments) with the independent parameters experiment number ( $n=3$ independent experiments) and treatment ( $n=2$, potencies vs controls)

\begin{tabular}{|l|l|r|r|}
\hline \multirow{2}{*}{$\begin{array}{l}\text { Experimental } \\
\text { series }\end{array}$} & Effects & \multicolumn{2}{|c|}{$\begin{array}{l}\text { p-Values for growth } \\
\text { rate }(\mathbf{r})\end{array}$} \\
\cline { 3 - 4 } & & day $\mathbf{0 - 3}$ & day 3-7 \\
\hline \multirow{3}{*}{ Merc-c. } & 1: Exp. no. & $<0.001$ & $<0.001$ \\
\cline { 2 - 4 } & 2: Treatment & $\mathbf{0 . 0 2 1}$ & 0.499 \\
\cline { 2 - 4 } & 1/2: Interaction & 0.136 & 0.494 \\
\hline \multirow{3}{*}{ SNC } & 1: Exp. no. & $<0.001$ & $<0.001$ \\
\cline { 2 - 4 } & 2: Treatment & 0.284 & 0.951 \\
\cline { 2 - 4 } & 1/2: Interaction & 0.235 & 0.176 \\
\hline
\end{tabular}

Note: Data of the seven potency levels (24x to 30x) and the seven control samples (three samples of unsuccussed water, four samples of succussed water) were pooled into two groups. For the analysis of the SNC experiments, the randomisation codes of the Merc-c. experiments were applied. Measurement parameters were frond area-related growth rates for two different time intervals (day 0-3 and 3-7). Data were normalised to the mean of the pooled water controls for every individual experiment. Significant values $(p<0.05)$ related to treatment effects are shown in bold.

experiments with the randomisation from all three Merc-c. experiments. The results of these analyses did not yield any evidence for false-positive results due to the specific randomisation lists used for the Merc-c. experiments (-Table 3).

Table 3 ANOVA analysis of the three independent single SNC experiments with the randomisation of the three Merc-c. experiments each

\begin{tabular}{|l|l|l|l|}
\hline Experiment & Randomisation & \multicolumn{2}{|l|}{$\begin{array}{l}\text { p-Values for } \\
\text { growth rate (r) }\end{array}$} \\
\cline { 3 - 4 } & & day 0-3 & day 3-7 \\
\hline \multirow{3}{*}{$\begin{array}{l}\text { SNC } \\
\text { Exp. no. 1 }\end{array}$} & Merc-c. 1 & 0.210 & 0.443 \\
\cline { 2 - 4 } & Merc-c. 2 & 0.852 & 0.459 \\
\cline { 2 - 4 } & Merc-c. 3 & 0.429 & 0.983 \\
\hline \multirow{3}{*}{$\begin{array}{l}\text { SNC } \\
\text { Exp. no. 2 }\end{array}$} & Merc-c. 1 & 0.470 & 0.781 \\
\cline { 2 - 4 } & Merc-c. 2 & 0.644 & 0.466 \\
\cline { 2 - 4 } & Merc-c. 3 & 0.302 & 0.718 \\
\hline \multirow{3}{*}{ SNC } & Merc-c. 1 & 0.309 & 0.482 \\
\cline { 2 - 4 } & Merc-c. 2 & 0.278 & 0.772 \\
\cline { 2 - 4 } & Merc-c. 3 & 0.385 & 0.088 \\
\hline
\end{tabular}

Abbreviations: ANOVA, analysis of variance; SNC, systematic negative control. Note: Data were allocated into two groups, corresponding to the randomisation codes of the Merc-c. experiments (group 1: beakers corresponding to the seven potency levels (24x-30x); group 2: beakers corresponding to the 7 control samples). Measurement parameter was frond area-related growth rate for two different time intervals (day $0-3$ and 3-7). No significant values $(p<0.05)$ related to treatment effects were found.

\section{Succussion Effect}

To account for unspecific physico-chemical effects occurring during the succussion step of the potentisation process (increased ion dissolution from the vessel walls, $\mathrm{pH}$ alteration due to $\mathrm{CO}_{2}$ dissolution etc.), unsuccussed and succussed water controls from all experiments with potentised substances were compared, as proposed by Baumgartner et al. ${ }^{25}$ In ANOVA F-tests of growth rate data, no significant succussion effect and no significant interaction with experiment number were observed for any outcome parameter (-Table 4). Since succussed water (c1) did not differ from unsuccussed water (c0) in its effects on duckweed growth rate, we concluded that possible unspecific effects due to the succussion procedure were negligible in this test system. Therefore, as had been defined a priori, effects of potentised substances (see below) were compared with the pooled data from both control groups (defined as control c) to increase statistical power and to balance the number of samples in the group with pooled potencies and the group of controls.

\section{Effects of Merc-c. (24x-30x, Pooled Data)}

Duckweed growth rate data (area-related growth rates for the two time intervals) for the experimental series were analysed separately, always in full two-way ANOVA with the independent variables treatment ( $n=2$, all potency levels versus pooled controls) and experiment number (1-3). Results are given in -Table 2 and in -Fig. 2 for the arearelated growth rate (day $0-3$ and day $3-7$ ).

Homeopathic potencies of Merc-c. reduced the growth rate of severely mercury-stressed Lemna gibba L. compared with water controls (frond area growth rate $[r]$, day $0-3$ [ $p=0.021]$, - Table 2). The stress-induced growth inhibition of $49 \%$ increased by $2.7 \%$ to $51.7 \%$ on the average of all potencies. Growth rates in the second time interval (day 3-7) were not influenced by the homeopathic treatment.

\section{Effects of Merc-c. (24x-30x, Single Potency Levels)}

Duckweed growth rate data (area-related growth rates for the two time intervals) were analysed in full two-way ANOVA with the independent variables treatment $(n=9$, seven potency levels and two controls) and experiment number (1-3). Results for area-related growth rate are given in - Table 5 (day 0-3 and 3-7) and in -Fig. 3 (day 0-3). The

Table 4 Comparison (ANOVA F-tests) of unsuccussed (c0) and succussed controls (c1) for two time intervals (day 0-3 and 3-7)

\begin{tabular}{|l|l|r|r|}
\hline \multirow{2}{*}{$\begin{array}{l}\text { Experimental } \\
\text { series }\end{array}$} & Effects & \multicolumn{2}{|l|}{$\begin{array}{l}\text { p-Values for growth } \\
\text { rate }(\mathbf{r})\end{array}$} \\
\cline { 3 - 4 } & & day $0-3$ & day 3-7 \\
\hline \multirow{3}{*}{ Merc-c } & 1: Exp. no. & $<0.001$ & $<0.001$ \\
\cline { 2 - 4 } & 2: Treatment & 0.740 & 0.977 \\
\cline { 2 - 4 } & 1/2: Interaction & 0.721 & 0.948 \\
\hline
\end{tabular}

Abbreviation: ANOVA, analysis of variance; Exp. no., experiment number. Note: Data were taken from the Merc-c. experimental series with three independent experiments. No significant values $(p<0.05)$ related to treatment effects were found. 


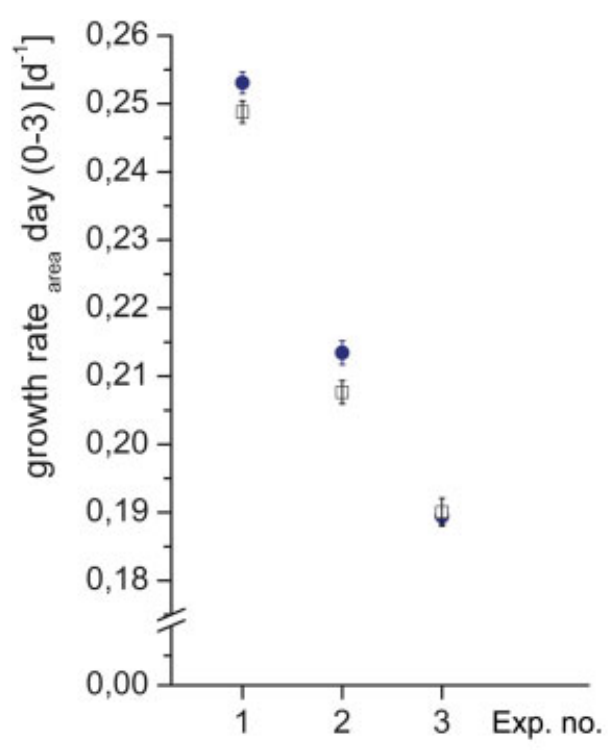

Merc-c. $24 \mathrm{x}-30 \mathrm{x}$

A controls

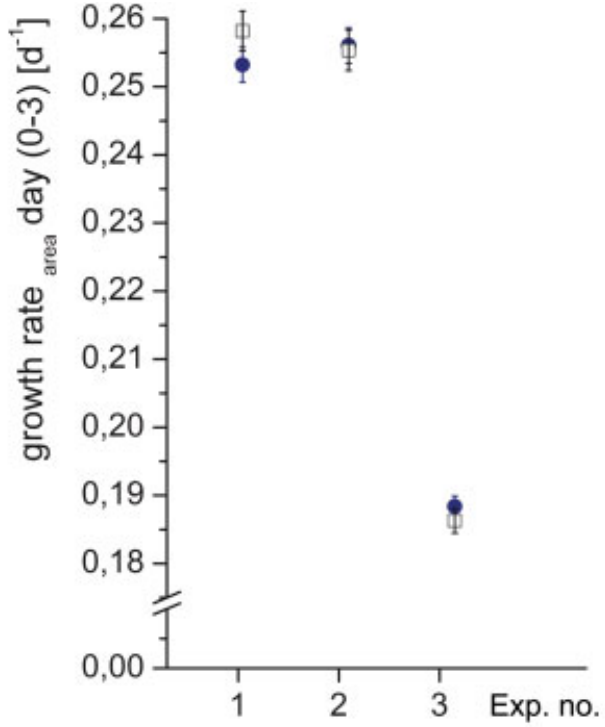

$\begin{array}{ll}\text { B } & \text { systematic negative controls (I) } \\ \text { - systematic negative controls (II) }\end{array}$

Fig. 2 Growth rate of Lemna gibba L. ( $r$, day $0-3)\left[\mathrm{d}^{-1}\right]$ (mean \pm standard error) treated with Mercurius corrosivus. (A) Data for the seven potency levels $(24 x-30 x)$ were pooled and compared with the pooled data for the seven control samples (three samples of unsuccussed water, four samples of succussed water). The systematic negative control experiment (B) compared $7 \times 4$ beakers of unsuccussed water (systematic negative controls (I)) with another $7 \times 4$ beakers of unsuccussed water (systematic negative controls (II)), using the randomisation of the three Merc-c. experiments. The two experimental series (A, B) comprised three independently performed experiments each (Exp. no.).

SNC experiments were analysed analogously, with randomised allocation of the beakers to the sham treatment parameters (w0-w8).

In this analysis, significant homeopathic treatment effects were observed in the Merc-c. series for the area-related growth rate for day $0-3$. Regarding single potency levels, $26 \mathrm{x}$ and $27 \mathrm{x}$ of Merc-c. significantly reduced the main outcome parameter growth rate for day $0-3$. The stress-induced growth inhibition of $49 \%$ increased by $6.4 \%$ on the average of the two potency levels $26 \mathrm{x}$ and $27 \mathrm{x}$. For the same test interval (day 0-3), we found significant effects for the interaction of treatment with experiment number (-Table 5, Series Merc-c.).

\section{Sensitivity Analysis of Treatment Effects}

We performed a sensitivity analysis regarding the stability of the growth-inhibiting effects induced by Merc-c. on the growth rate $(r)$ for days 0 to 3 . Eliminating extreme values of growth rate ('outliers') with $2.0 \times$ SD did not substantially influence the significance levels of the $F$-test for the main analysis of variance treatment effect (comparing either Mercc. with the pooled controls or comparing controls with controls in the SNC experiments, -Table 6). Hence, the results are stable and not due to some extreme values.

\section{General Discussion}

Growth rate of severely mercury-stressed duckweed was reduced after application of Merc-c. as measured in terms of frond area for day 0 to $3(p<0.05)$. Due to the inherent use of SNC experiments that did not yield any significant effects and due to additional control calculations, false-positive results can be excluded with a very high degree of certainty.
Table 5 Analysis of variance (ANOVA) of the two experimental series (potentised test substance Mercurius corrosivus as well as systematic negative control (SNC) experiments) with the independent parameters experiment number

\begin{tabular}{|l|l|r|r|}
\hline \multirow{2}{*}{$\begin{array}{l}\text { Experimental } \\
\text { series }\end{array}$} & Effects & \multicolumn{2}{|c|}{$\begin{array}{l}\boldsymbol{p} \text {-Values for growth } \\
\text { rate }(\mathbf{r})\end{array}$} \\
\cline { 3 - 4 } & & day $\mathbf{0 - 3}$ & day $\mathbf{3 - 7}$ \\
\hline \multirow{3}{*}{ Merc-c } & 1: Exp. no. & $<0.001$ & $<0.001$ \\
\cline { 2 - 4 } & 2: Treatment & $\mathbf{0 . 0 1 2}$ & 0.844 \\
\cline { 2 - 4 } & 1/2: Interaction & $\mathbf{0 . 0 1 9}$ & 0.555 \\
\hline SNC & 1: Exp. no. & $<0.001$ & $<0.001$ \\
\cline { 2 - 4 } & 2: Treatment & 0.964 & 0.952 \\
\cline { 2 - 4 } & 1/2: Interaction & 0.751 & 0.798 \\
\hline
\end{tabular}

Measurement parameters were frond area-related growth rates for two different time intervals (day $0-3$ and $3-7)$. Significant values $(p<0.05)$ related to treatment effects are shown in bold.

Note: Independent experiments $(n=3)$ and treatment $(n=9$, seven potency levels (24x to 30x) and two controls (c0, c1) in the Merc-c. experiments, or nine samples of unpotentised controls in the SNC experiments, respectively).

In previous experiments, treatment of slightly arsenicstressed duckweed with potencies of Arsenicum album yielded growth-enhancing effects, measured in the growth period of day 2 to 6 , but not in the growth period of day 0 to $2^{21}$

We hypothesise that the growth inhibition induced by Merc-c. potencies is a consequence of the more pronounced stress in the present experiments. We propose a stress- 
Mercurius corrosivus

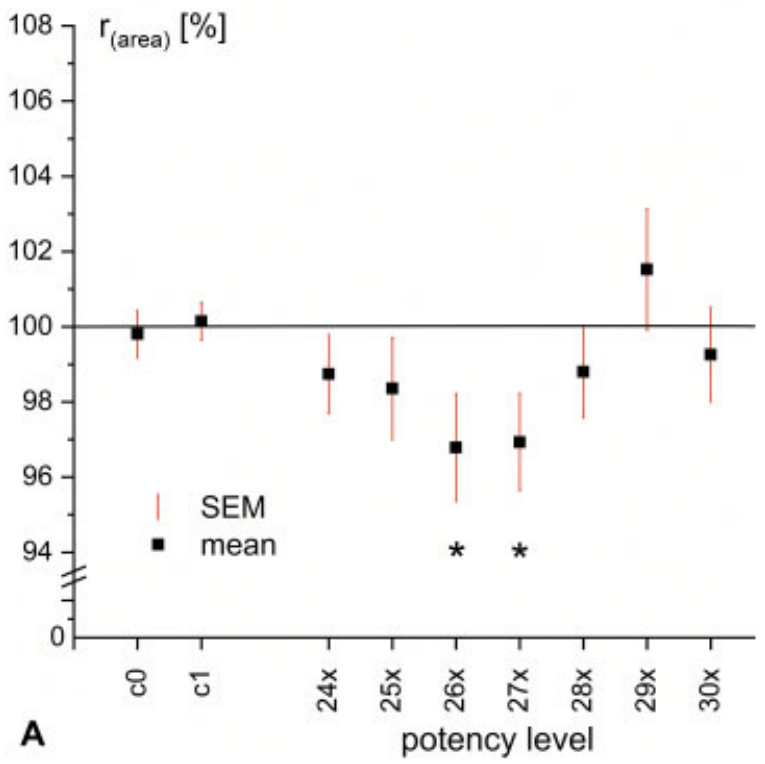

Systematic Negative Control (SNC) experiments

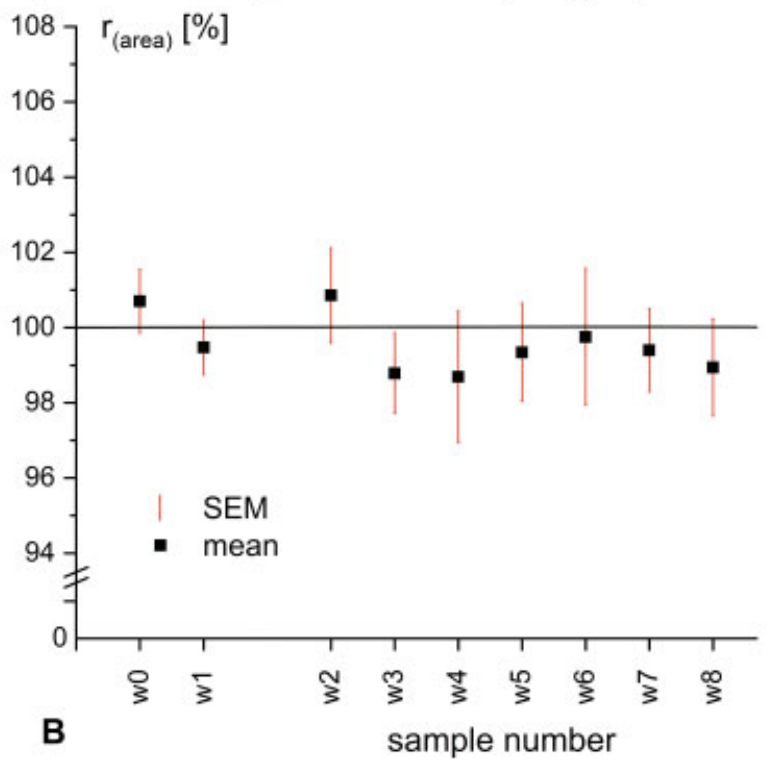

Fig. 3 Relative area-related growth rates ( $r$, day 0-3) [\%] of Lemna gibba L. growing in different potency levels of Mercurius corrosivus in comparison to the corresponding water controls (unsuccussed water (c0) and succussed water (c1)) (A). Part (B) shows the corresponding graph for the systematic negative control (SNC) experiments with samples of identical origin (unsuccussed water = dilution medium used). Mean values (dots) \pm standard error (bars) for three independent experiments are shown. Every data point for single potency levels is an average from three independent experiments with four replicates (beakers) each ( $n=12$ per data point plotted). The two data points for controls are an average from three independent experiments with 16 beakers (succussed controls $\mathrm{c} 1$ ) or 12 beakers (unsuccussed controls $\mathrm{c} 0)(n=48$ and $n=36$ per data point plotted). Data were normalised to the experimental mean of succussed and unsuccussed water controls $(c 0+c 1)$ for each individual experiment. Statistically significant differences (Fisher's protected least significant difference test) between single potency levels and the pooled water control $\mathrm{c}$ are indicated by ${ }^{*}(0.01<p<0.05)$.

response model with five ranges: (1) Low stress with no significant homeopathic effect; (2) moderate stress with a significant growth-enhancing effect of the homeopathic treatment; (3) medium stress with neutralised effects; (4)

Table 6 Analysis of variance (ANOVA) F-test statistics for the main treatment effect of the outcome parameter growth rate ( $r$ ) day 0 to 3, as a function of excluded extreme values (2.0, and $3.5 \times$ standard deviation [SD])

\begin{tabular}{|l|l|l|l|}
\hline $\begin{array}{l}\text { Experimental } \\
\text { series }\end{array}$ & $\begin{array}{l}\text { Outlier limit } \\
(x \times \text { SD) }\end{array}$ & $2.0 \times$ SD & $3.5 \times$ SD \\
\hline \multirow{5}{*}{ Merc-c } & Outliers ( $n)$ & 8 & 0 \\
\cline { 2 - 4 } & Outliers (\%) & 4.8 & 0 \\
\cline { 2 - 4 } & $\begin{array}{l}\text { p-Value } \\
\text { (potencies vs } \\
\text { controls) }\end{array}$ & $\mathbf{0 . 0 4 4}$ & $\mathbf{0 . 0 2 1}$ \\
\hline SNC & Outliers ( $n)$ & 7 & 0 \\
\cline { 2 - 4 } & Outliers (\%) & 4.2 & 0 \\
\cline { 2 - 4 } & $\begin{array}{l}\text { p-Value } \\
\text { (controls vs } \\
\text { controls) }\end{array}$ & 0.387 & 0.284 \\
\hline
\end{tabular}

Treatment effect compared pooled data from Mercurius corrosivus potency levels ( $24 x$ to $30 x$ ) with pooled data from both water control (succussed and unsuccussed), or unsuccussed control with unsuccussed control in the systematic negative control (SNC) experiments.

Three independent experiments with test substance Mercurius corrosivus or three independent negative control experiments were included (SNC, Mercurius corrosivus; each 168 data points in total). Significant values $(p<0.05)$ are shown in bold.

Note: No more extreme values were found with $3.5 \times$ SD of growth rates. severe stress with a significant growth-inhibiting effect after homeopathic treatment; and (5) very severe stress without homeopathic treatment effect (-Fig. 4).

According to this model, the organisms react with growth inhibition in the first growth period of day 0 to 3, in which the stress is severe (range 4 , immediately after stress application) compared with a medium stress in the later growth period day 3 to 7 (range 3), where no homeopathic treatment effects were observed. The findings of previous experiments, ${ }^{21}$ in which potencies of Arsenicum album yielded growth-enhancing effects in slightly arsenic-stressed duckweed for day 2 to 6 , would correspond to range 2 (moderate stress); correspondingly, the zero treatment effect for day 0 to 2 in the experiments with Arsenicum album would correspond to range 3 (medium stress).

The proposed stress-response model would also explain the correlation between homeopathic treatment effect and poisoning effect in the Arsenicum album experiments with duckweed ( $\mathbf{- F i g . ~ 5 , ~ S p e a r m a n ~ c o r r e l a t i o n ~} p=0.037$ ). This correlation strongly supports the hypothesis of a dependency of the magnitude of effect on the degree of damage. Furthermore, the appropriate degree of damage needed to observe a therapeutic effect of the homeopathic treatment seems to fall within quite a small range. For the experiments with Arsenicum album, we would rate the stress as between range 2 and 3 of our model (-Fig. 4), since the less-stressed duckweed showed a stronger response to potentised preparations than the more severely stressed duckweed.

Missing or reverse effects in basic homeopathy research ${ }^{18,29-34}$ could be explained by a relatively small range 


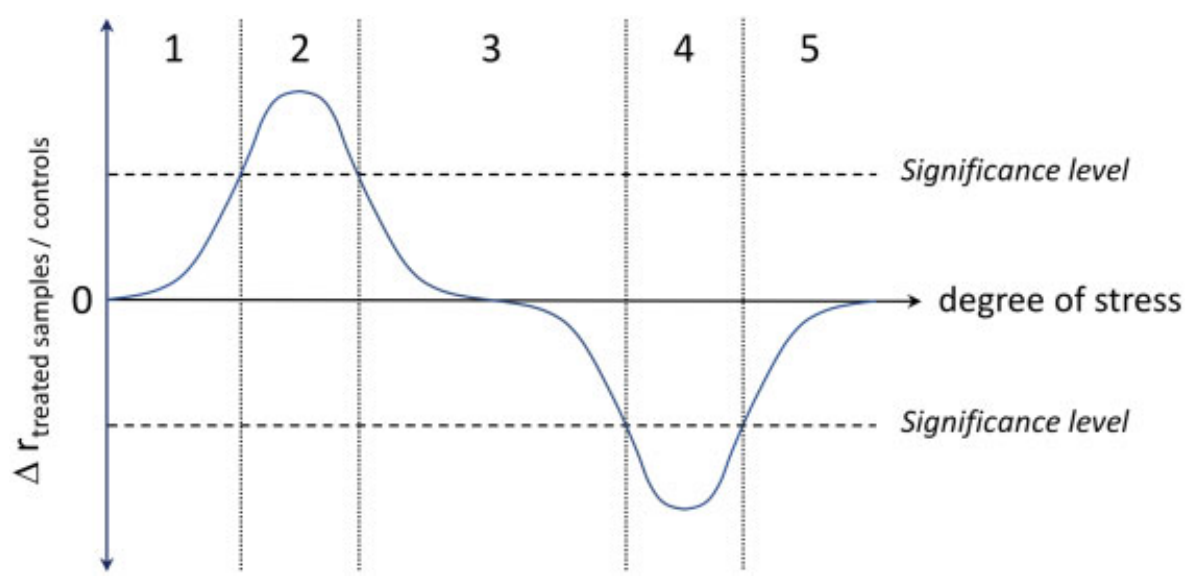

Fig. 4 Hypothesis for the homeopathic treatment response as a function of different stress levels. Diagrammatic plot (proportions not based on experimental data) of difference in growth rates between treated and untreated plants ( $\Delta r$ ) as a function of degree of stress for Lemna gibba $\mathrm{L}$. Five ranges are proposed: (1) low stress with no significant homeopathic treatment effect; (2) moderate stress with a significant stress-relieving effect from homeopathic treatment; (3) medium stress with neutralised effects; (4) severe stress with a significant inhibiting effect from homeopathic treatment; (5) very severe stress with no homeopathic treatment effect.

of stress levels appropriate for inducing a therapeutic effect of potentised preparations in organisms. A narrow response range may also be the reason that no effects were found in experiment no. 3 of this study with mercury-stressed duckweed. In experiment no. 3 , the degree of stress was the highest of all three experiments (-Fig. 2), corresponding to stress range 5 in our model ( - Fig. 4). Postulating a steep gradient of the relation between effect of potentised substances and stress level, minor differences in the stress level may lead to zero or inversed effects of potentised substances.

The control calculations conducted in the present and previous experiments involving stressed duckweed ${ }^{21}$ indicate that the effects of potentised preparations cannot be reduced to artefacts. Furthermore, systematic errors would not lead to

\section{Plant: Lemna gibba L. \\ Stressor: As(V) \\ Homeopathic treatment: Arsenicum album}

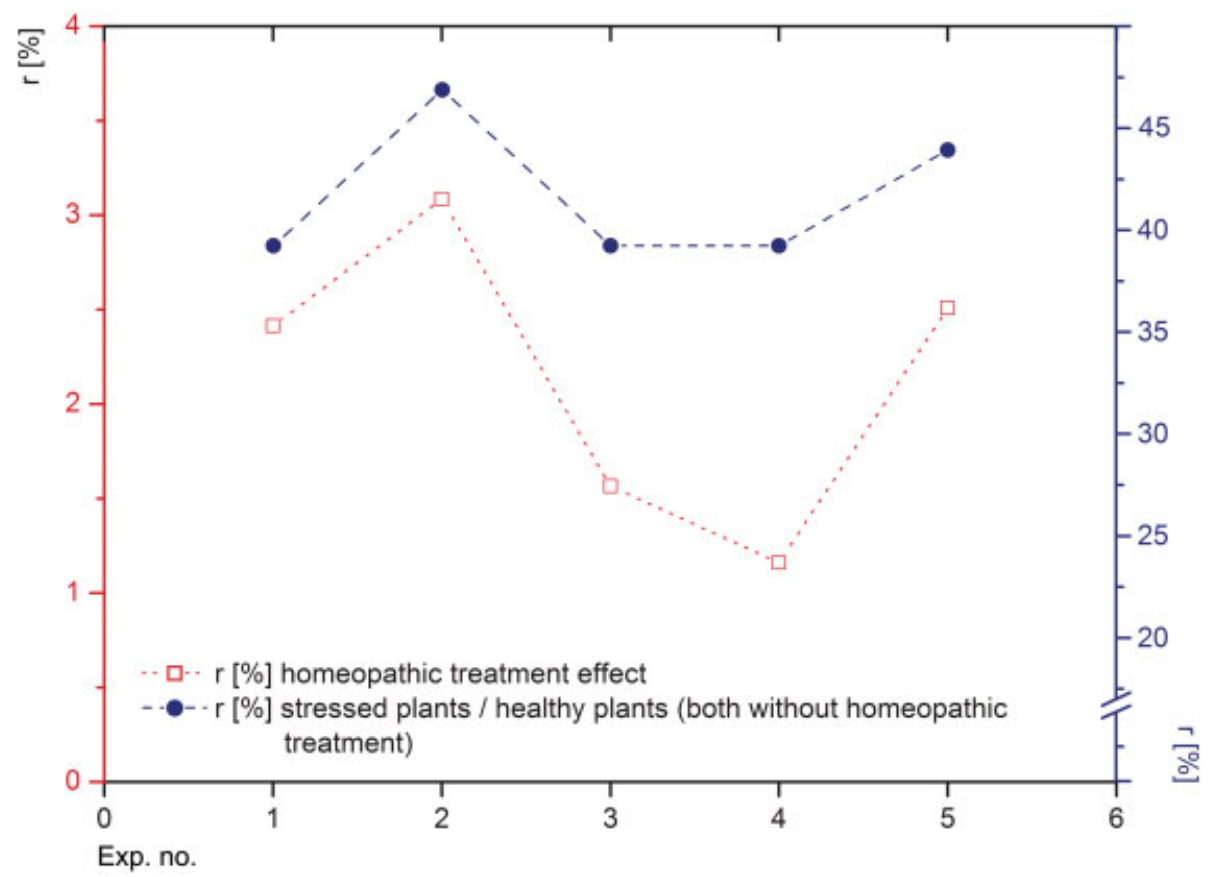

Fig. 5 Left axis (squares): Homeopathic treatment effect (relative growth rate of homeopathically treated Lemna gibba L. relative to untreated Lemna gibba L., $\mathrm{r}$ [\%] day 2-6, both after arsenic stress). Right axis (filled circles): Relative growth rate of arsenic-stressed Lemna gibba L. compared with unimpaired Lemna gibba L. ( $r$ [\%] day 2-6), both without homeopathic treatment. ${ }^{21}$ Lemna gibba L. were treated with potencies of Arsenicum album. Data for the nine potency levels (17x, 18x, 21x-24x, 28x, 30x, 33x) were pooled and compared with the pooled data for the nine control samples (four samples of unsuccussed water, five samples of succussed water). ${ }^{21}$ The experimental series comprised five independently performed experiments (Exp. no.). Lines connecting data points are not interpolations. 
growth-enhancing or growth-inhibiting effects as a function of stress level. Reverse effects controlled by the degree of stress would support the notion that the duckweed bioassay with stressed organisms is a highly stable test system.

The potency levels 26x and 27x of Merc-c. significantly inhibited duckweed growth rate, while the other potency levels did not. There seems to be a non-linear relationship between successive potency levels and effect, with 'active' and 'inactive' potency levels. Such effects have been reported in duckweed experiments showing growth-enhancing effects ${ }^{21}$ and in almost every basic research investigation examining series of potencies. ${ }^{11}$ From the reverse effects of homeopathic preparations depending on the stress level in the present bioassay, it remains an open research question if it is possible to draw conclusions regarding the homeopathic treatment of more complex organisms like animals and humans.

Merc-c. 26x and 27x, corresponding to a nominal concentration of $7.5^{-29} \mathrm{~g} \mathrm{HgCl}_{2} / \mathrm{L}$ and $7.5^{-30} \mathrm{~g} \mathrm{HgCl}_{2} / \mathrm{L}$, respectively -that is, well beyond the Avogadro limit-significantly influenced duckweed growth rate. Significant effects from preparations beyond the Avogadro limit have also been reported for duckweed experiments with growth-enhancing effects, ${ }^{21}$ as well as in several other studies. ${ }^{29,35-40}$ Specific effects at these high dilution levels, where the probability of finding any molecules of the potentised substance is extremely low, are not indicative of molecular-based interactions of material nature, but perhaps suggest informational and/or force-like (non-material) effects. Part of a prospective research approach, however, should also reflect the question of any nanoparticles of mercury being present in the homeopathic preparations used. ${ }^{41-43}$

We did not observe any effect of the succussion procedure itself in this bioassay. Thus, duckweed does not seem to react to physico-chemical changes induced by the succussion of water in glass vessels (increased level of glass ions, air suspension and dissolution). ${ }^{44,45}$ These results are also in line with other experiments with stressed duckweed ${ }^{21}$ and further recent investigations with various biological test systems where no significant effects of water succussion have been observed. 17,46,47

Potentised medicines may cause an equalising effect on variance. ${ }^{48}$ To test this assumption, all single experiments with Merc-c. (growth rate [r], day $0-3$ ) were analysed by Levene's test for a difference in variance between the pooled potency levels and pooled controls. No significant differences were found (data not presented).

\section{Outlook}

To further confirm or to dismiss the hypothesis of antagonistic effects as a function of stress intensity, the experiments of this study should be repeated with moderately stressed duckweed. For use in future research projects, the present experimental set-up might be further optimised by adjusting several experimental parameters: for example modalities of application, time of impairment in relation to time of homeopathic treatment, measurement time and growth conditions (light and temperature regimen). Restricting the range of the tested potency levels to 'active' levels and then increasing the number of replicates per potency level would be another way to enhance the effect size of the test system. Particularly interesting potency levels might be $26 \mathrm{x}$ and $27 \mathrm{x}$, since the present study found pronounced effects at these two potency levels.

A further topic of research is the similia principle, which could be investigated by varying the stressors and the applied potentised substances. One question, for example, is whether the growth of arsenic-stressed duckweed-physiologically very similar to mercury-stressed duckweed-could be enhanced by Merc-c. and vice versa. Further down the line, it might be interesting to test a combination of medicines, such as mercury and arsenic (both heavy metals) or other potentised preparations such as Mercurius bijodatus, in contrast to the here used isopathic preparation Merc-c. (mercury(II) chloride), using both severely and moderately stressed duckweeds.

Continuing research is needed to reveal the specific nature of the biological effects induced in duckweed. Metabolomic analysis could be supportive in two ways. First, it could serve as an additional measurement parameter for comparison between homeopathically treated and untreated duckweeds. Second, the metabolomes of moderately and severely stressed duckweed could be analysed in comparison to defined chemical pathways activated by the homeopathic treatment. Any such results might contribute to our understanding of the biological mode of action of homeopathic preparations.

Future potential applications of this test system include testing the influence of certain pharmaceutical procedures (e.g. autoclaving, trituration versus dilution, machine potentisation) or other external influences (e.g. heat, light, electromagnetic radiation) that might affect stability and quality of homeopathic preparations. The investigations of external influences might also help to reveal the physico-chemical mode of action.

\section{Conclusion}

The present experimental set-up with severely mercurystressed Lemna gibba L. yielded significant effects compared with water controls for the outcome parameter frond area ( $p<0.05, F$-test). In contrast to slightly stressed duckweed, where potentised preparations were observed to induce a growth-enhancing effect, ${ }^{21}$ an inhibiting effect on growth was observed in this study with severely stressed duckweed. We hypothesise that duckweed has a range of stress levels that is associated with differing directions of effects of homeopathic preparations.

\section{Highlights}

- A test system with Lemna gibba L. that was severely stressed by mercury yielded effects of Merc-c. $24 \mathrm{x}-30 \mathrm{x}$ : namely a growth reduction in the first time period (day 0-3).

- This is in contrast to former experiments with slightly arsenic-stressed duckweed, where a growth increase was observed in the second time period (day 2-6).

- We hypothesise that the finding is due to the difference in stress intensity (severe versus slight). 


\section{Conflict of Interest}

None declared.

Acknowledgments

This investigation was funded by institutional resources only.

\section{References}

1 Relton C, Cooper K, Viksveen P, Fibert P, Thomas K. Prevalence of homeopathy use by the general population worldwide: a systematic review. Homeopathy 2017;106:69-78

2 World Health Organization. Legal Status of Traditional Medicine and Complementary/Alternative Medicine: A Worldwide Review. 2001. Available at: http://apps.who.int/medicinedocs/pdf/h2943e/ h2943e.pdf. Accessed June 2018

3 Dinges M. Die Homöopathie erobert die Welt, in: Europäische Geschichte Online (EGO), hg. vom Institut für Europäische Geschichte (IEG), Mainz; December 3, 2010. Available at: http:// www.ieg-ego.eu/dingesm-2010-de. Accessed June 2018

4 Turner A. Evaluating the UK House of Commons Science and Technology Committee's position on the implausible effectiveness of homeopathic treatments. Theor Med Bioeth 2017;38:335-352

5 Faculty of Homeopathy. Research. Available at: https://facultyofhomeopathy.org/research/. Accessed June 2018

6 Macdonald C, Gavura S. Alternative medicine and the ethics of commerce. Bioethics 2016;30:77-84

7 Fisher P, Ernst E. Should doctors recommend homeopathy? BMJ 2015;351:h3735

8 Weber S, Endler PC, Welles SU, et al. The effect of homeopathically prepared thyroxine on highland frogs: influence of electromagnetic fields. Homeopathy 2008;97:3-9

9 Chaplin MF. The memory of water: an overview. Homeopathy 2007;96:143-150

10 Weingärtner 0 . The nature of the active ingredient in ultramolecular dilutions. Homeopathy 2007;96:220-226

11 Baumgartner S. The state of the basic research in homeopathy Advice from an interdisciplinary conference. In: Witt C, Albrecht $\mathrm{H}$, eds. New Directions in Homeopathy Research. Essen: KVC Verlag; 2009:107-130

12 Water quality-determination of toxic effect of water constituents and waste water to duckweed (Lemna minor)-duckweed growth inhibition test. International Standard ISO 20079. Geneva: Switzerland; 2005

13 United States Environmental Protection Agency: OCSPP 850.4400 Aquatic Plant Toxicity Test Using Lemna spp., EPA 712-C-008, January 2012:8

14 OECD 221: Verordnung (EG) Nr. 440/2008, C.26, ISO 20079, DIN EN ISO 20079. Available at: http://www.oecd.org/chemicalsafety/ testing/1948054.pdf

15 Swedish Standard Institute: Water quality-determination of growth inhibition (7-d) Lemna minor, duckweed. SS 02 82 13; 1995:15

16 Environment Canada 1998 Biological test method: Test for measuring the inhibition of growth using the freshwater macrophyte Lemna minor Report EPS 1/RM/37, 2nd ed; 2007:137

17 Scherr C, Simon M, Spranger J, Baumgartner S. Effects of potentised substances on growth rate of the water plant Lemna gibba L. Complement Ther Med 2009;17:63-70

18 Majewsky V, Scherr C, Schneider C, Arlt SP, Baumgartner S. Reproducibility of the effects of homeopathically potentised Argentum nitricum on the growth of Lemna gibba L. in a randomised and blinded bioassay. Homeopathy 2017;106:145-154

19 Baumgartner S, Shah D, Schaller J, Kämpfer U, Thurneysen A, Heusser P. Reproducibility of dwarf pea shoot growth stimulation by homeopathic potencies of gibberellic acid. Complement Ther Med 2008;16:183-191

20 Hamman B, Koning G, Lok KH. Homeopathically prepared gibberellic acid and barley seed germination. Homeopathy 2003;92:140-144
21 Jäger T, Scherr C, Simon M, Heusser P, Baumgartner S. Effects of homeopathic arsenicum album, nosode, and gibberellic acid preparations on the growth rate of arsenic-impaired duckweed (Lemna gibba L.). Scientific World Journal 2010;10:2112-2129

22 United Nations Environment Programme. Text of the Minamata Convention on Mercury for adoption by the Conference of Plenipotentiaries. unep.org. July 31. Available at: https://treaties.un. org/doc/Treaties/2013/10/20131010\%2011-16\%20AM/CTC-XXVII17.pdf. Accessed June 2018

23 World Health Organization. Elemental mercury and inorganic mercury compounds: human health aspects. Available at: http:// www.who.int/ipcs/publications/cicad/en/cicad50.pdf. Accessed June 2018

24 Jäger T, Scherr C, Simon M, Heusser P, Baumgartner S. Development of a test system for homeopathic preparations using impaired duckweed (Lemna gibba L.). J Altern Complement Med 2011; 17:315-323

25 Baumgartner S, Heusser P, Thurneysen S. Methodological standards and problems in preclinical homeopathic potency research. Forsch Komplementarmed 1998;5:27-32

26 Carmer SG, Swanson MR. An evaluation of ten pairwise multiple comparison procedures by Monte Carlo methods. J Am Stat Assoc 1973;68:66-74

27 Nani D, Brizzi M, Lazzarato L, Betti L. The role of variability in evaluating ultra high dilution effects: considerations based on plant model experiments. Forsch Komplement Med 2007; 14:301-305

28 Binder M, Baumgartner S, Thurneysen $\mathrm{A}$. The effects of a $45 \mathrm{x}$ potency of arsenicum album on wheat seedling growth - a reproduction trial. Forsch Komplementarmed Klass Naturheilkd 2005;12:284-291

29 Lahnstein L, Binder M, Thurneysen A, et al. Isopathic treatment effects of Arsenicum album 45x on wheat seedling growthfurther reproduction trials. Homeopathy 2009;98:198-207

30 Jäger T, Scherr C, Shah D, et al. Use of homeopathic preparations in experimental studies with abiotically stressed plants. Homeopathy 2011;100:275-287

31 Ücker A, Baumgartner S, Sokol A, Huber R, Doesburg P, Jäger T. Systematic review of plant-based homeopathic basic research: an update. Homeopathy 2018;107:115-129

32 Endler PC, Bellavite P, Bonamin L, Jäger T, Mazon S. Replications of fundamental research models in ultra high dilutions 1994 and 2015update on a bibliometric study. Homeopathy 2015;104:234-245

33 Endler PC, Matzer W, Reich C, et al. Seasonal variation of the effect of extremely diluted agitated gibberellic acid (10e-30) on wheat stalk growth: a multiresearcher study. Scientific World Journal 2011;11:1667-1678

34 Scherer-Pongratz W, Endler PC, Lothaller H, Stephen S. Wheat and ultra high diluted silver nitrate - further experiments and reanalysis of data. Homeopathy 2015;104:246-249

35 Betti L, Lazzarato L, Trebbi G, et al. Effects of homeopathic arsenic on tobacco plant resistance to tobacco mosaic virus. Theoretical suggestions about system variability, based on a large experimental data set. Homeopathy 2003;92:195-202

36 Brizzi M, Elia V, Trebbi G, Nani D, Peruzzi M, Betti L. The efficacy of ultramolecular aqueous dilutions on a wheat germination model as a function of heat and aging-time. Evid Based Complement Alternat Med 2011;2011:696298

37 Brizzi M, Nani D, Peruzzi M, Betti L. Statistical analysis of the effect of high dilutions of arsenic in a large dataset from a wheat germination model. Br Homeopath J 2000;89:63-67

38 Endler PC, Lüdtke R, Heckmann C, et al. Pretreatment with thyroxine (10-(8) parts by weight) enhances a 'curative' effect of homeopathically prepared thyroxine (10-(13)) on lowland frogs. Forsch Komplementarmed Klass Naturheilkd 2003;10:137-142

39 Zausner C, Lassnig H, Endler PC, et al. Die Wirkung von »homöopathisch" zubereitetem Thyroxin auf die Metamorphose von Hochlandamphibien-Ergebnisse einer multizentrischen Kontrollstudie. Perfusion (Nürnberg) 2002;15:268-276 
40 Betti L, Zurla M, Trebbi G, Brizzi M, Borghini G, Borghini F. Extremely low doses of arsenic affect in vitro pollen germination. Forsch Komplement Med 2013;20:254-260

41 Bell IR, Muralidharan S, Schwartz GE. Nanoparticle characterization of traditional homeopathically-manufactured silver (Argentum Metallicum) medicines and placebo controls. J Nanomed Nanotechnol 2015;6:311

42 Chikramane PS, Suresh AK, Kane SG, Bellare JR. Metal nanoparticle induced hormetic activation: a novel mechanism of homeopathic medicines. Homeopathy 2017;106:135-144

43 Van Wassenhoven M, Goyens M, Capieaux E, Devos P, Dorfman P. Nanoparticle characterisation of traditional homeopathically manufactured Cuprum metallicum and Gelsemium sempervirens medicines and controls. Homeopathy 2018;107:244-263

44 Ives JA, Moffett JR, Arun P, et al. Enzyme stabilization by glassderived silicates in glass-exposed aqueous solutions. Homeopathy 2010;99:15-24
45 Witt CM, Lüdtke R, Weisshuhn TE, Quint P, Willich SN. The role of trace elements in homeopathic preparations and the influence of container material, storage duration, and potentisation. Forsch Komplement Med 2006;13:15-21

46 Baumgartner S, Thurneysen A, Heusser P. Growth stimulation of dwarf peas (Pisum sativum L.) through homeopathic potencies of plant growth substances. Forsch Komplementarmed Klass Naturheilkd 2004;11:281-292

47 Scherr C, Baumgartner S, Spranger J, Simon M. Effects of potentised substances on growth kinetics of Saccharomyces cerevisiae and Schizosaccharomyces pombe. Forsch Komplement Med 2006; 13:298-306

48 Brizzi M, Lazzarato L, Nani D, Borghini F, Peruzzi M, Betti L. A biostatistical insight into the $\mathrm{As}_{2} \mathrm{O}_{3}$ high dilution effects on the rate and variability of wheat seedling growth. Forsch Komplementarmed Klass Naturheilkd 2005;12:277-283 